\title{
Article \\ A Comparative Study of Signal Processing Methods for Contactless Geodetic Monitoring
}

\author{
Samo Lubej * and Boštjan Kovačič
}

Citation: Lubej, S.; Kovačič, B. A Comparative Study of Signal Processing Methods for Contactless Geodetic Monitoring. Appl. Sci. 2021, 11, 11276. https://doi.org/10.3390/ app112311276

Academic Editor: Stojan Kravanja

Received: 15 November 2021

Accepted: 24 November 2021

Published: 28 November 2021

Publisher's Note: MDPI stays neutral with regard to jurisdictional claims in published maps and institutional affiliations.

Copyright: (C) 2021 by the authors Licensee MDPI, Basel, Switzerland. This article is an open access article distributed under the terms and conditions of the Creative Commons Attribution (CC BY) license (https:/ / creativecommons.org/licenses/by/ $4.0 /)$.
Faculty of Civil Engineering, Transportation Engineering and Architecture, University of Maribor, Smetanova 17, SI-2000 Maribor, Slovenia; bostjan.kovacic@um.si

* Correspondence: samo.lubej@um.si; Tel.: +3-862-229-4333

\begin{abstract}
Building structures are subject to various deformations caused by external and internal factors. Deformations are determined by various methods in the form of monitoring. It is very important to monitor the dynamic vibration response on bridge structures since these measurements allow us to identify any possible damage over time and take appropriate action. Our experiment, described in this article, is based on the use of non-contact methods, among which we used a geodetic instrument RTS (Robotic Total Station) and a seismograph to measure vibrations. The purpose and novelty of our work are reflected in the use of geodetic instruments to determine the dynamic response and synchronization of the obtained results. When using RTS technology, we increased data acquisition from 9 to 26 measurements per second. Comparative analysis of the measured signals was performed using FFT (Fast Fourier Transformation) and LSP (Lomb-Scargle Periodogram), based on LSSA (Least-Squares Spectral Analysis). The results showed us that when using the RTS geodetic instrument, it is possible to achieve frequency spectra comparable to those measured with a seismograph instrument. By increasing the number of measurements, the RTS method can be used to obtain more continuous data, which are essential for dynamic analyses.
\end{abstract}

Keywords: vibration monitoring; dynamic bridge movements; robotic total station; geodesy

\section{Introduction}

Nowadays, the monitoring of bridging structures is mostly based on measuring the displacements, deformations, and vibrations of bridges. Data on the static and dynamic behavior of a structure under load are usually obtained by a load test. Data on the longterm behavior of facilities are obtained by load testing and continued monitoring. This is important for heavily loaded objects on highways or railroads. The technological development of measuring equipment has also intervened in the field of geodetic instruments. The measurement can be performed in several ways. The group of alternative methods includes geodetic (optical) measurements, which can be static or dynamic. Measuring systems can be contact or non-contact. In practice, displacements are measured only at certain points with a limited set of measuring instruments, which requires a lot of time to prepare measuring points. The result of the non-contact measuring system is the movement of individual points in different places. In addition to making optical systems more accurate, measurements are more transparent and there is virtually no preparation for measurement. Automatic capture of measured values allows us to quickly and reliably determine the position of points. Because the processing of oscillation signals is conditioned by the sampling frequency, the measurement accuracy is improved by increasing the readings per second. Until recently, only vertical and horizontal displacements could be determined by geodetic measurements. Today, with the development of geodetic equipment, increasing resolution, additional sensors for faster reading, and automatic prism monitoring, it is possible, when geodetic measurements are taken together with very accurate static measurements, to perform dynamic response measurements in various monitoring [1,2]. It should be noted that geodetic methods can be used in a very simple way to obtain quality data on the 
behavior of struction in locations where this would not be possible due to inaccessibility or difficulty with other methods.

The problem of determining the actual deformations of buildings under the influence of dynamic loads has been unsolved from the point of view of geodesy until recently. Systematic measurements of displacements of more flexible struction structures (e.g., bridges, tall buildings) began to be carried out with the advent of advanced geodetic devices such as GNSS, which enabled the capture of a sufficient number of position measurements in a certain time interval. The system works on the principle of connection with satellites, so the condition for performing such measurements is an unobstructed view of the horizon and the presence of a sufficient number of satellites. Problems occur in narrow basins and ravines or in urban settlements, where a clear path to the satellites is difficult to ensure throughout the measurement. With the development of two-frequency systems, today, we can perform measurements according to the system of the relative method using phase (real-time kinematic-RTK), thus avoiding problems with the satellite signal.

Due to the possibility of determining the 3D position of points in motion in an absolute system with the ability to read from 1 to 100 measurements per second, the GNSS method has become useful in addition to static measurements also suitable for dynamic research. Today's GNSS equipment allows us to read between 10 and $20 \mathrm{~Hz}$. The development of GNSS technology today allows us to measure with a frequency of $50 \mathrm{~Hz}$ as well as up to $100 \mathrm{~Hz}$ [3-9].

The shortcomings of the GNSS method, such as multipath, poor satellite distribution, the unreliability of the elevation component, and other known shortcomings, are complemented by the introduction of additional geodetic measurements with the RTS method. The dynamic measurements of structures are mostly contaminated by dynamic noise, which is worsened by the errors caused by the GNSS monitoring techniques. Therefore, before studying the dynamic behavior of a structure, the de-noising, smoothing, and filtering methods should be applied to eliminate the effects of noise [10].

Various authors [11-22] mainly dealt with the synchronization of the measurement signal obtained by the RTS method, which is essential for further dynamic response analyses.

With the development of technology and additional programs, the lack of synchronization is eliminated. If the struction, working conditions, weather, and time allow, it makes sense to use several independent measurement methods and to compare the measured values. The method of comparison was described in the work of Lekidis et al., 2005 [18]. Today, modern geodetic instruments and sensors such as GNSS, RTS, and Scanners can be used for static and dynamic bridge monitoring [1], which are the main part of a bridge's load test after its construction, reconstruction, or remediation.

Nowadays, the RTS system is mainly used, which enables automatic prism monitoring up to a speed of $30 \mathrm{~Hz}$, which is enough for dynamic monitoring of objects in the range of a few centimeters [8-14]. Increasing the number of complaints allows an additional program, which controls the RTS station via a laptop The software was developed at the Faculty of Geodesy in Zagreb (Zagreb, Croatia) and allows us to make two types of measurements: measurements of length, $\mathrm{Hz}$ (horizontal angles) and $\mathrm{V}$ (vertical angles) angle in milliseconds and measurements of $\mathrm{Hz}$ and $\mathrm{V}$ angle only, whereby, due to the exclusion of the distance measurement, it is possible to make several more regular measurements per second $[14,15]$.

To better understand the behavior of the structure, it is reasonable to perform measurements with different independent non-contact methods and compare the results, as presented in [22]. Recently, many authors [23-30] have been concerned with the use and accuracy of the results obtained with GNSS and terrestrial scanners in the determination of the structural response and in various types of object monitoring.

In this paper, we give an example of a new way of performing measurements of the dynamic response of a bridging structure using two completely different measuring techniques. RTS was used to measure displacements on two separate structures in the vertical direction of the structure oscillation. In parallel with these measurements, we performed 
vibration velocity measurements with a seismograph and an associated geophone. Based on the measured physical values, the program was used to analyze the dynamic response of the bridging structure.

\section{The Purpose of Study}

The monitoring of displacements and deformations is necessary primarily for the protection of lives and property and to determine the condition of structures. There are many methods for monitoring displacements, and the purpose of our work is to upgrade already known methods and perform synchronization and comparison of results obtained with different methods. In this work, we used a robotic total setting, which with an additional program, increased the possibility of capturing data from 9 to 26 measurements per second. The program allows different combinations of measurements depending on what we need. A novelty in the paper is the analysis, comparison, and synchronization of the obtained measurements with emphasis on the results of RTS in determining the dynamic response of the structure.

\section{Materials and Methods}

Monitoring to determine the dynamic response of the bridging structure was carried out on a pedestrian and bicycle bridge across the Drava River in Maribor, Slovenia. The dynamic response of the structure was measured using geodetic instruments and a seismograph with a triaxial geophone, which is classified as a group of physical instruments. The pedestrian bridge is a steel space bar structure, $126 \mathrm{~m}$ long, with three spans of $42 \mathrm{~m}$ each. The point at which we measured the dynamic response of the induced vibration was on the main longitudinal steel bridge girder in the middle of the first span, as shown in Figure 1.
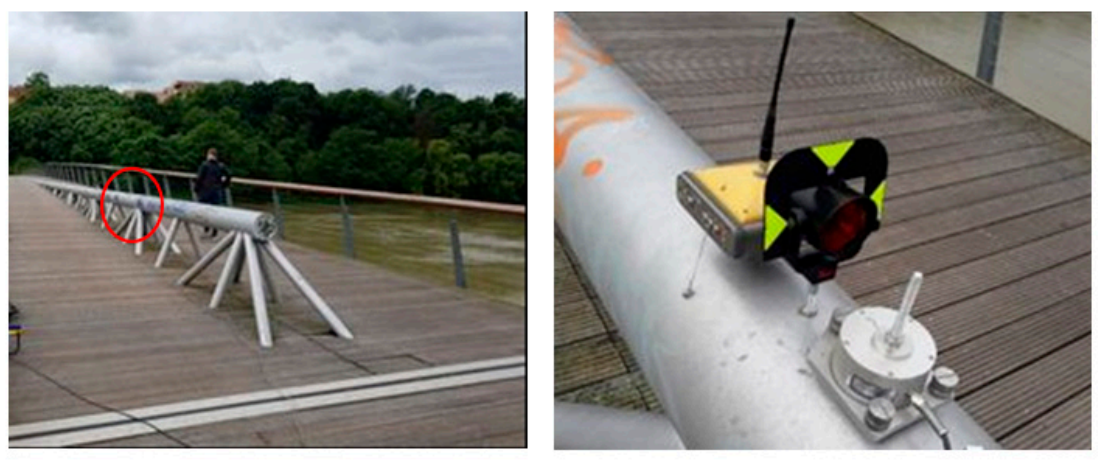

Figure 1. Location of the measuring point on the bridge over the river Drava.

Vibrations for measuring the dynamic response of the bridging structure were induced by two people with a total mass of $160 \mathrm{~kg}$ running away from the measuring point. Geodetic measurements were performed with two Total Robotic Station (RTS) Leica TS50 and TS30. The apparatus measures the change in the horizontal and vertical angles to the geodetic target. The third measuring device was the Topcon Hiper Pro Global Navigation Satellite System (GNSS), which allows dynamic observation of a measuring point based on measured distances to satellites. Physical measurements were performed using an Instantel Minimate Plus seismograph with a triaxial geophone. The basic characteristics of measuring equipment are shown in Table 1. 
Table 1. Basic characteristics of measuring equipment.

\begin{tabular}{|c|c|c|}
\hline \multicolumn{3}{|c|}{ Geodetic Measurement Equipment } \\
\hline Sensor & Measuring Equipment & $\begin{array}{l}\text { Frequency of Signal } \\
\text { Acquisition }(\mathrm{Hz})\end{array}$ \\
\hline RTS50 & $\begin{array}{c}\text { RTS Leica TS50 + } \\
\text { GeoCOM/ZG }\end{array}$ & $26-30$ \\
\hline RTS30 & RTS Leica TS30 & $6-10$ \\
\hline GNSS & GNSS Topcom Hiper Pro & 10 \\
\hline \multicolumn{3}{|c|}{ Physical Measuring Equipment } \\
\hline Sensor & Measuring Equipment & $\begin{array}{l}\text { Frequency of Signal } \\
\text { Acquisition (Hz) }\end{array}$ \\
\hline ACC1 & Instantel Minimate Plus & 250 \\
\hline
\end{tabular}

For the experiment, we used the Leica TS50 and TS30 robotic tachymeters shown in Figure 2. The instruments were placed on undeformable terrain, $19.5 \mathrm{~m}$ away from the Leica GPR121 target. The instruments automatically track the target and are capable of sampling frequencies up to $20 \mathrm{~Hz}$. The TS50 and TS30 instruments have declared factory accuracies: according to ISO 17123-3 for angular measurements of $0.5 \mathrm{~s}$ or $0.15 \mathrm{mgons}$ and according to ISO $17123-4$ for spacings of $0.6 \mathrm{~mm}+1 \mathrm{ppm}$. The TS30 recorded data at a frequency of $6 \mathrm{~Hz}$, while for the TS50, we used the GeoCom/Zg add-on program, which recorded results at a frequency of $26 \mathrm{~Hz}$.

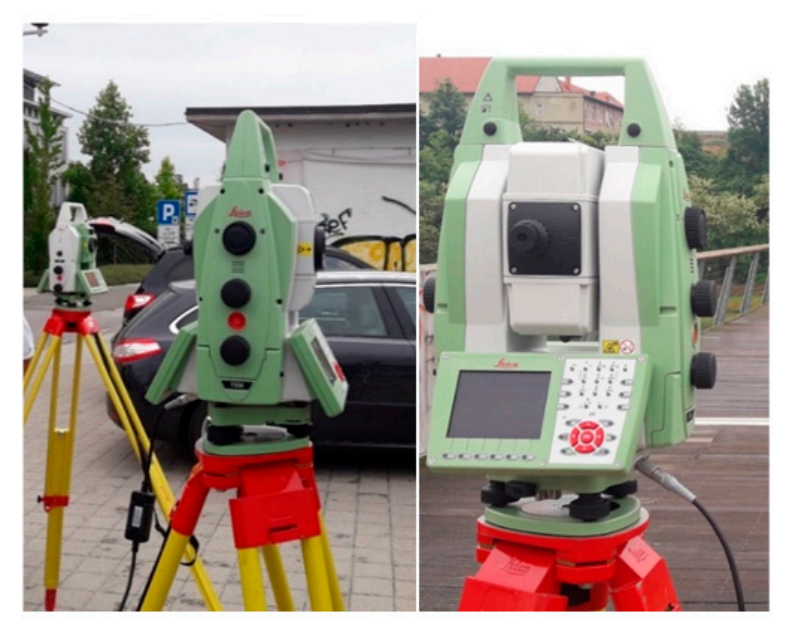

Figure 2. Geodetic instruments Leica TS30/50 for monitoring.

The software uses a GEV269 cable to connect the instrument to a laptop. As mentioned earlier, the software can measure angles, lengths, and time, or just angles and time (Figure 3). When testing the program, it was found that switching off the distance measurement gives more uniform results [31]. When determining the dynamic response parameters, it is sufficient to only record the changes along the vertical direction.

Determining the position with the GNSS receiver in the first phase is based on the so-called pseudo-distance or on determining the distances to selected satellites in space. The latter have precisely defined points with perfectly known coordinates. The receiver locally creates a duplicate copy of the signal, which it receives as feedback from the satellite, and then compares the signal thus generated with the originally received signal. The comparison or adjustment of the measured point takes long enough that the receiver completely equates its locally generated signal with the received one, which is reflected in reaching the peak of the cross-correlation function between the signals. Only with full coverage is the signal decoded into a navigation message from which satellite position information can be deduced. The determination of the position in the field is performed by measuring 
four distances to four different satellites, as only in this case is a uniform determination of the three-dimensional position possible. To determine the exact position, modern GNSS receivers combine different signals and, at the same time, address observations using a geodetic code and phase. GNSS measurement methods are, by their nature, divided into relative and absolute methods. Absolute methods represent much more generalized approaches and are more valid than personal navigation methods, as their accuracy does not exceed a few meters. Relative methods are measurement methods with GNSS systems whereby high accuracy can be achieved. In such methods, one receiver, named a reference or base, is positioned in a place with known or unknown coordinates, and the other, a movable receiver (rover), is positioned in a place where we determine the position of new points [32]. In our experiment, we used the RTK (base-rover) method with a reading speed of $0.1 \mathrm{~s}$ (Figure 4). The static GNSS method would be quite useless in our case, due to the presence of too many metal parts near the antenna that would interfere with the satellite signal receiver and due to the confinement of the terrain.

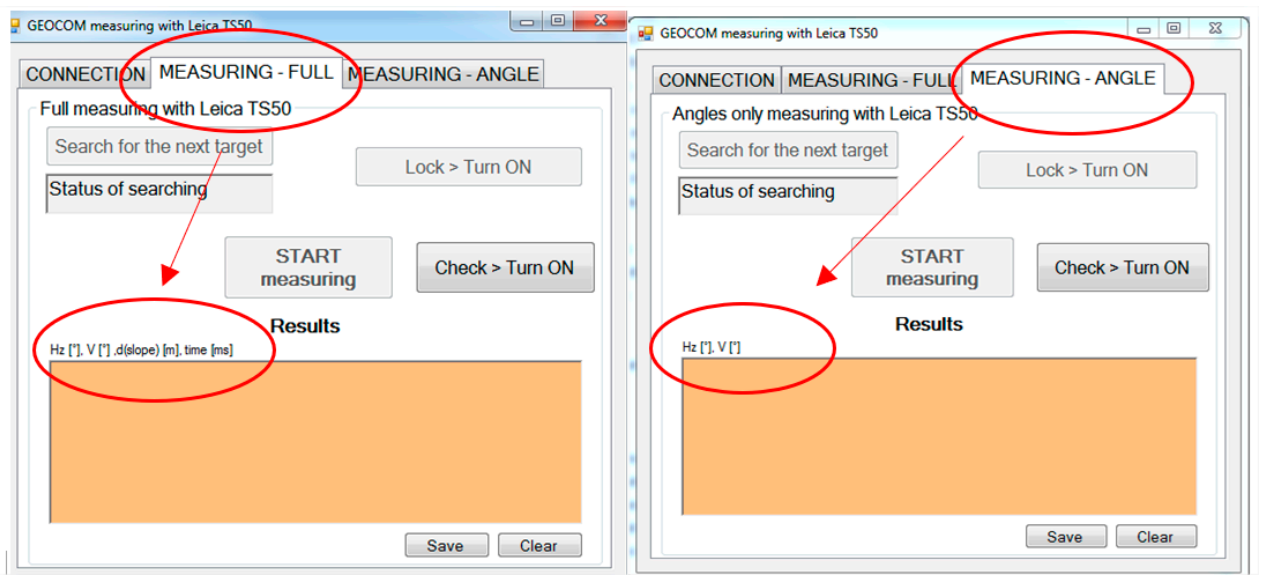

Figure 3. The GeoCOM/ZG program (left: all measurements, right: only measuring angles).

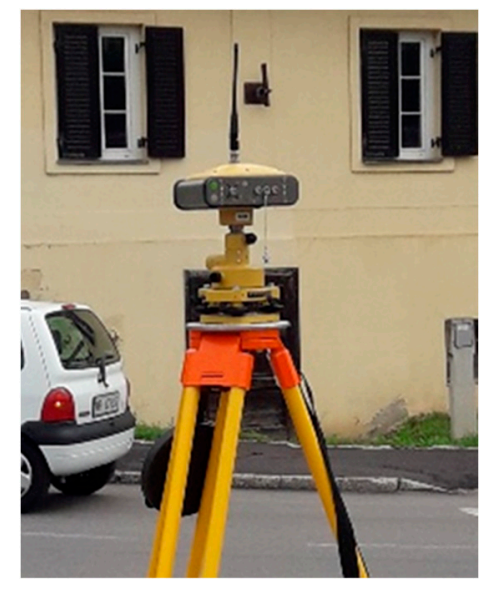

Figure 4. Base station Topcon Hyper Pro.

The dynamic response of the constriction was induced by two persons running with a total mass of $160 \mathrm{~kg}$. Measurements in most scientific and engineering fields are characterized by the periodic signal of the measured objects, with periodicity determined by spectral analysis. 
In the field of spectral analysis, the most widely used technique is the Fourier transform calculation method. The Fourier transform has the disadvantage of requiring a constant (equivalent) measurement interval [32].

The Fourier transform is used in many mathematical fields. The main reason for using this method is to convert the complex operations of interpretation and convolution into a simple multiplicative operation. Thus, the Fourier transform is an important tool in solving differential equations.

Uniform sampling can only be recorded with advanced automated measurement systems, such as accelerometers or strain gauges, which allow us to capture measurements up to $2000 \mathrm{~Hz}$. In contrast to these, non-contact methods have the problem of non-uniform sampling, where data are acquired at regular or irregular time intervals. This is due to the inherent technical shortcomings of the instruments. These errors are considered to be gross errors due to insufficient frequencies, noise, and mechanical interruptions of the measurements.

The Fourier transform becomes practically useless if the analysis considers results at unequal intervals. To solve this problem, Nicholas R. Lomb and Jeffrey D. Scargle introduced the Lomb periodogram method, which allows spectral analysis of irregularly (and also correctly) sampled measurement data. The Lomb (or Lomb-Scargle) periodogram is based on the principle of least squares, and the procedure is based on fitting sine functions to the shape [32-34]:

$$
h(t)=a \cdot \cos \left(\frac{2 \pi}{T} \cdot(t-\tau)\right)+b \cdot \sin \left(\frac{2 \pi}{T} \cdot(t-\tau)\right) .
$$

The Lomb periodogram $P(t)$ describes a non-dimensional value with which the spectral power is expressed. For time period $T$, it is defined as [33,34]:

$$
P(T)=\frac{1}{2 \sigma^{2}} \cdot\left\{\frac{\left[\sum_{j=1}^{N}\left(x_{j}-\bar{x}\right) \cdot \cos \frac{2 \pi\left(t_{i}-\tau\right)}{T}\right]^{2}}{\sum_{j=1}^{N} \cos ^{2} \frac{2 \pi\left(t_{i}-\tau\right)}{T}}+\frac{\left[\sum_{j=1}^{N}\left(x_{j}-\bar{x}\right) \cdot \sin \frac{2 \pi\left(t_{i}-\tau\right)}{T}\right]^{2}}{\sum_{j=1}^{N} \sin ^{2} \frac{2 \pi\left(t_{i}-\tau\right)}{T}}\right\},
$$

where in the equation for the time lapse, the parameter $\tau$ is defined as:

$$
\tan \left(\frac{4 \pi \tau}{T}\right)=\frac{\sum_{j=1}^{N} \sin \left(\frac{4 \pi \tau_{i}}{T}\right)}{\sum_{j=1}^{N} \cos \left(\frac{4 \pi \tau_{i}}{T}\right)}
$$

where:

$N$... the size of the data block;

$t_{i} \ldots$ time of the measured displacement $i$;

$\bar{x} \ldots$ mean value of the displacement, calculated with the term $\bar{x}=\frac{1}{N} \cdot \sum_{i=1}^{N} x_{i} ;$ and

$\sigma^{2} \ldots$ standard deviation, calculated with the expression $\sigma^{2}=\frac{1}{N-1} \cdot \sum_{i=1}^{N}\left(x_{i}-\bar{x}\right)^{2}$.

The resulting extreme positive values of the Lomb-Scargle periodogram, which appear at the location of the frequencies that reduce the sum of squares when the value is fitted to a time-sine oscillation, give an approximation of the amplitude, as shown in Figures 5 and 6 and Table 2. 


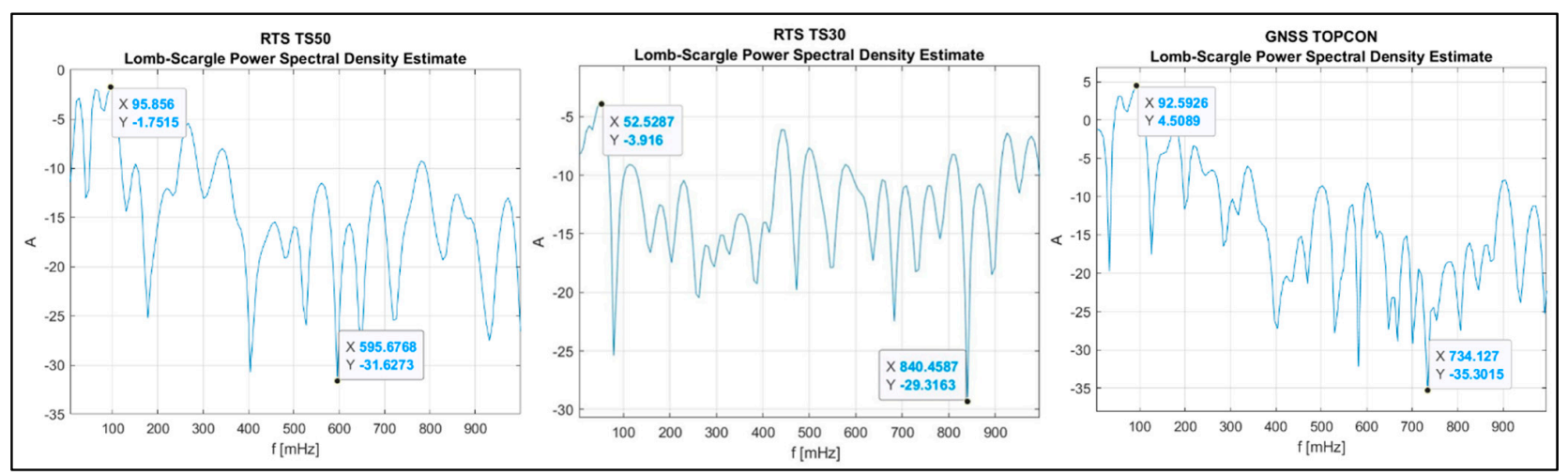

Figure 5. Lomb-Scargle periodogram for the frequency range between 0 and $1 \mathrm{~Hz}$.

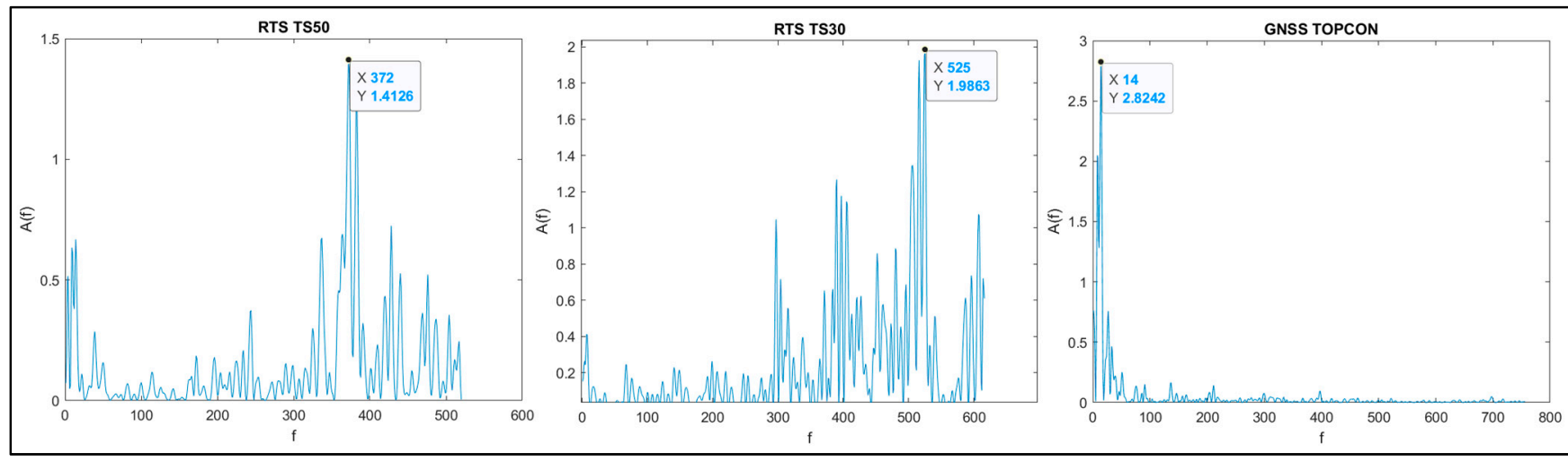

Figure 6. The entire frequency spectrum of the Lomb-Scargle periodogram.

Table 2. Measured values obtained by geodetic methods.

\begin{tabular}{cccc}
\hline & & Geodetic Measurement Equipment \\
\hline Measured Value & RTS TS50 $(\mathbf{2 6} \mathbf{~ H z})$ & $\begin{array}{c}\text { RTS TS30 } \\
\mathbf{( 6 ~ H z )}\end{array}$ & $\begin{array}{c}\text { GNSS Topcon Hiper Pro } \\
\mathbf{( 1 0 ~ H z )}\end{array}$ \\
\hline Vertical displacement $(\mathrm{mm})$ & 5.9329 & 5.7000 & 27.00 \\
Lomb-Scargle & 29.8758 & 25.4003 & 39.8104 \\
A(f) $(\mathrm{mm})$ & 1.4126 & 1.9863 & 2.8242 \\
Dominant frequency (Hz) & 2.5555 & 3.3116 & 0.0781 \\
Vertical amplitude (mm) & 0.5200 & 0.4046 & 4.8623 \\
\hline
\end{tabular}

The first row of Figure 5 shows the Lomb-Scargle periodogram (a spectral approximation for the range between 0 and $1 \mathrm{~Hz}$ of the fundamental signal), and the third row shows $A(f)$ for the full Lomb-Scargle periodogram, where $A(f)$ is calculated from Equation (2).

\section{Results}

The analysis of the measured signals was performed using the Fast Fourier Transformation (FFT) and the Lomb-Scargle periodogram (LS). The Blastware Advanced Module hardware was used to analyze the signals measured with the seismograph, and the GeoCOM/Zg computer program developed by the Faculty of Geodesy, University of Zagreb-Croatia, was used to analyze the signals measured with the geodetic equipment.

Figures 5 and 6 show the frequency spectra of the response of the structure due to the induced vibration, which was measured with geodetic measuring equipment. The summary of the vibration measurement results is given in Table 2.

Figure 7 on the left side shows a graph of vertical displacements as a result of geodetic measurement equipment, and Figure 7 on the right shows a graph of Peak Particle Velocity 
Vertical (PPV V) obtained by analyzing the signals measured with a seismograph. The graphs show that the graphs are very similar in shape.
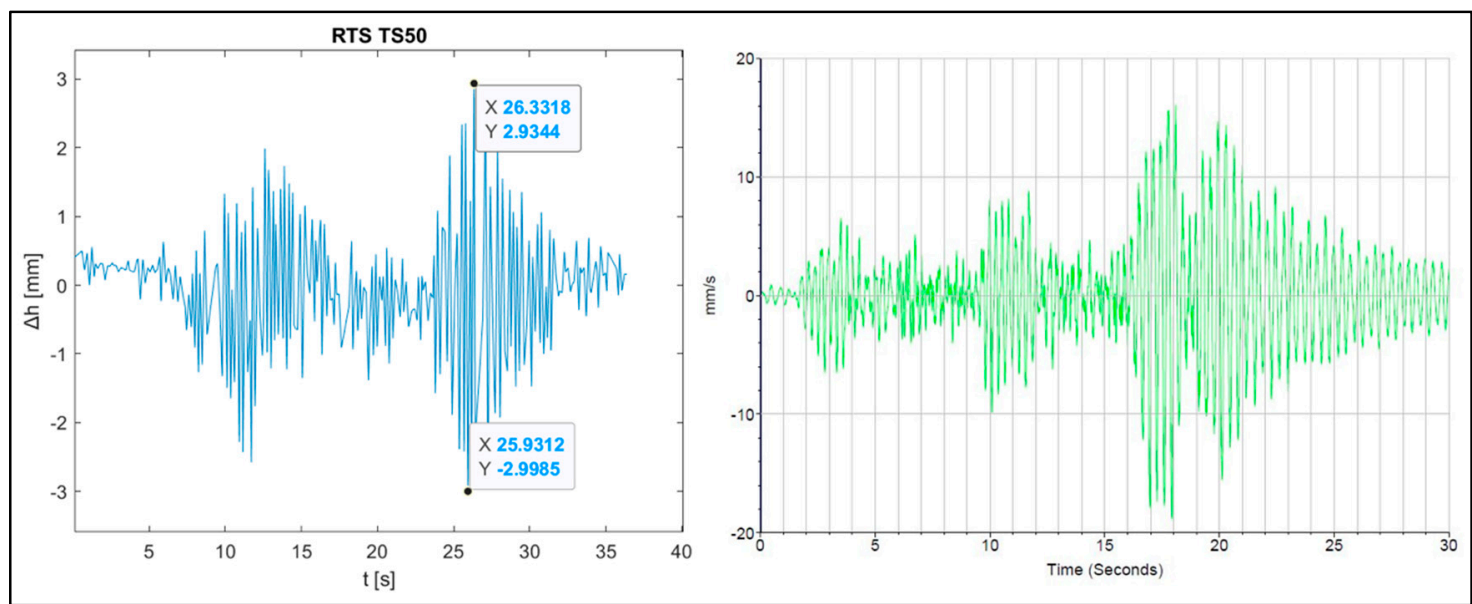

Figure 7. Comparison between graphs of vertical displacement (left) and vibration velocity (PPV V) (right).

Figure 8 shows the vibration velocities' Peak Particle Velocity in all three orthogonal directions-Transversal, Vertical and Longitudinal, measured by the seismograph.

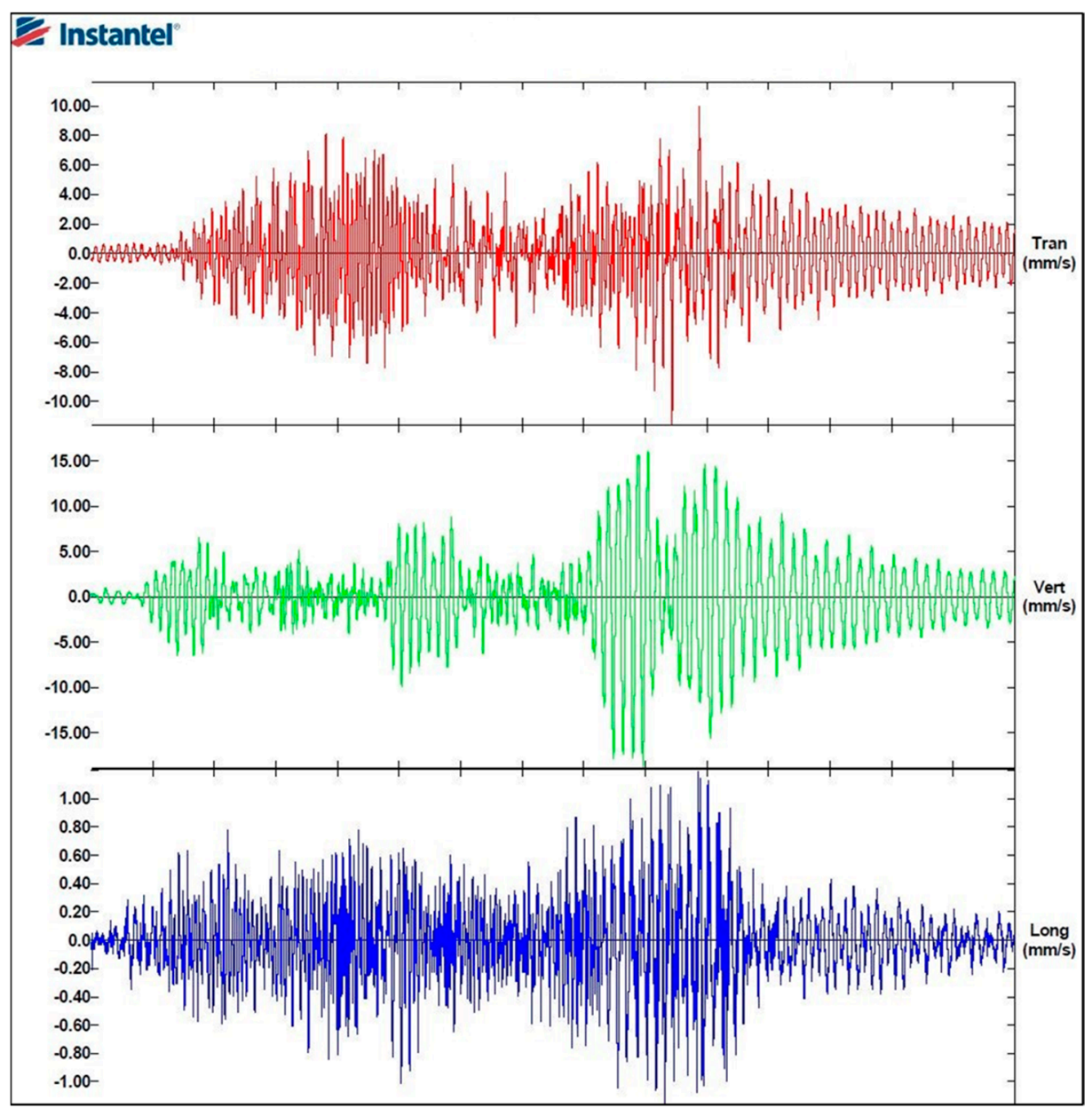

Figure 8. Peak Particle Velocity graph. 
The frequency spectrum of the signal over the entire measurement period in the vertical direction as a result of the FFT analysis is shown in Figure 9. The vertical axis shows the amplitude value, and the horizontal axis shows the frequency.

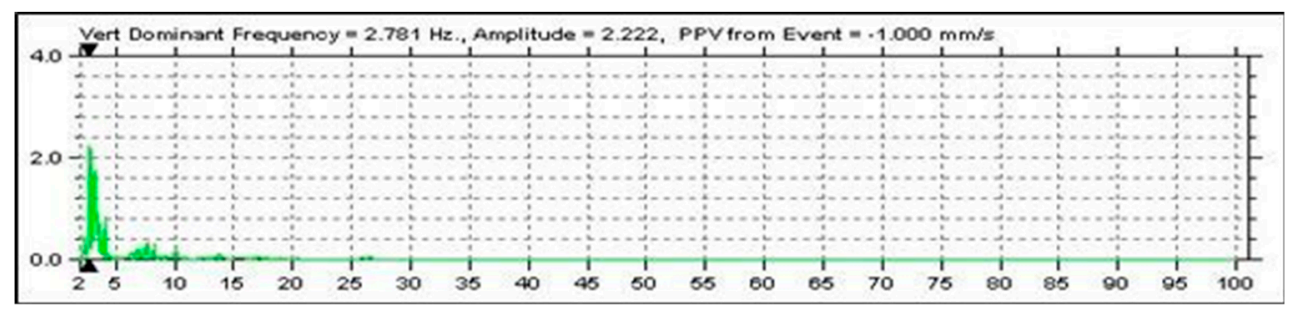

Figure 9. FFT analysis (Blastware Software 10.74- Advanced Module) for vibration measurements.

A comparison of the frequency spectra obtained with surveying equipment and the values of relative displacements and velocities of vibration shows:

The most important parameters are hereinafter described:

- The graphs of the vertical displacements and the corresponding vibrational velocities in the vertical direction coincide and can also be compared only on the basis of graphs.

- Extreme value locations coincide relatively well.

- Phase graphs of vibration velocities and vertical displacements can be seen as a result of vibration excitation at different spans of the bridging structure.

- The dominant frequencies are generally relatively comparable.

- The amplitudes and measured displacements are generally incomparable.

Table 3 shows the values of vertical displacements, dominant frequencies, and vertical amplitudes, which were calculated by analyzing the signals of the geodetic measuring equipment and the seismograph. We do not give the values of the data that were calculated by analyzing the signals of the Topcon Hiper Pro measuring equipment because they are not comparable due to the lack of precision of this equipment. Furthermore, the calculated displacement measured by the seismograph is not comparable as it represents the relative value of this quantity.

Table 3. Analysis-comparison of results.

\begin{tabular}{cccc}
\hline & RTS TS50 & RTS TS30 & MinimatePlus \\
\hline Vertical displacement $(\mathrm{mm})$ & 5.9329 & 5.7000 & 0.893 \\
Dominant frequency $(\mathrm{Hz})$ & 2.5555 & 3.3116 & 2.781 \\
Vertical amplitude $(\mathrm{mm})$ & 0.5200 & 0.4046 & 2.222 \\
\hline
\end{tabular}

Therefore, it can be concluded that the results of geodetic and physical measurements in the event under consideration were comparable from the standpoint of the corresponding graphical trajectories of the measured signals and the corresponding dominant frequencies obtained by spectral analysis.

\section{Discussion}

The measurements we performed at the bridging objects enabled us to analyze the induced vibrations, which were performed taking into account the results of representative measurements with different measuring equipment. The presented monitoring of the dynamic response of bridging structures using geodetic and physical measuring instruments represents a unique way that provides a comprehensive insight into the behavior of such structures. The use of algorithms such as FFT and LS gives very good results of the frequency range of the oscillation of the structure. Our measurements have shown that even with geodetic instruments, if the appropriate sampling frequency is enabled, we can very accurately measure the dynamic response of the bridging structure. The comparison 
of frequency spectra obtained with the described measuring equipment confirms the consistency of the source signals and the matching of the frequency spectra. The practical use value of such monitoring is also confirmed by the comparable accuracy of the results.

Based on the comparative analysis of individual measurements with RTS TS50 measuring and geodetic equipment and on the basis of the described available literature, we found that the highest accuracy of measurements was achieved at frequencies lower than $20 \mathrm{~Hz}$. The highest achieved oscillation frequency was $30 \mathrm{~Hz}$, which according to Nyquist's sampling theorem, would mean that we would need measuring instruments with a minimum frequency of $60 \mathrm{~Hz}$. However, currently available geodetic equipment does not allow such sampling. Said measuring equipment can be measured in the frequency range between 20 and $30 \mathrm{~Hz}$.

\section{Conclusions}

Methods of the dynamic response of building structures for struction practice represent an extremely important area. With such measurements, we obtain the information needed to analyze the behavior of structures. There are many ways to perform such measurements, but today in this area, preference is given to methods that can be performed using contactless monitoring with which we can observe the structure very accurately at a relatively large distance regardless of the size and accessibility of measuring points. Geodetic non-contact monitoring is based on the analysis of measured signals. In our case, we performed monitoring with three different geodetic instruments on the bridging structure, which was loaded with four mutually different load tests. We used two robotic total stations (RTS Leica TS30 and RTS Leica TS50) and a global navigation receiver (GNSS Topcon Hiper Pro). Simultaneously with the geodetic monitoring, we also performed measurements with the help of physical measuring equipment Instantel Minimate Plus, which helped us to compare and evaluate the accuracy of the measured values with which we can control the dynamic response of such structures. For each type of equipment used, we performed an analysis of the results of the measured values.

The general finding of the useful value of measurements with GNSS measuring equipment is that this equipment enables the monitoring of the dynamic response, but the results of the dynamic monitoring are not sufficiently accurate for struction practice. We found that for a frequency spectrum above $10 \mathrm{~Hz}$ accompanied by small displacements, the measurements are not accurate enough. This equipment is only useful for measuring larger displacements at low frequencies over a long period of time. The error of the GNSS method in our case can be attributed to the incorrectly selected RTK method. To determine the dynamic response, it would make more sense to use the static GNSS method, which provides us with more accurate and reliable results.

In the analysis of monitoring with RTS geodetic equipment, we found that the results obtained in the frequency range between 6 and $26 \mathrm{~Hz}$ are comparable. We observed minor deviations on the basis of which we can conclude that the frequency of signal capture has a decisive influence on the accuracy of measured values.

In analyzing the results, we found that the use of algorithms for spectral analysis such as FFT and LS represents a very good mathematical tool that allows the interpretation of the frequency components of the oscillation.

Both used total robotic stations-RTS in the frequency range between 6 and $26 \mathrm{~Hz}$ enabled engineeringly accurate monitoring. The mutual comparison of the results of dynamic response measurements with geodetic measuring equipment determined by the dominant frequency is, in all cases, a comparable value, even in the case of measurements with physical measuring equipment.

Monitoring the dynamic response of a bridging structure with geodetic and physical equipment presented in this article provides representative and useful results for struction practice. The use of geodetic monitoring, which must be monitored by physical monitoring, represents a very reliable and technically perfect possibility for monitoring the behavior of the facility during its use. 
Author Contributions: Conceptualization, B.K. and S.L.; methodology, S.L.; software, B.K.; validation, B.K. and S.L.; formal analysis, B.K.; investigation, S.L. and B.K.; resources, B.K.; data curation B.K. and S.L.; writing-original draft preparation, B.K. and S.L.; writing-review and editing, B.K. and S.L.; visualization, B.K.; supervision, S.L.; project administration, B.K. All authors have read and agreed to the published version of the manuscript.

Funding: This research received no external funding.

Institutional Review Board Statement: Not applicable.

Informed Consent Statement: Not applicable.

Data Availability Statement: The data presented in this study are available on request from the corresponding author. The data are not publicly available. The data were obtained on the basis of own research within the master's thesis of Luka Muršec at the Faculty of Civil engineering, Transportation Engineering and Architecture, University of Maribor.

Conflicts of Interest: The authors declare no conflict of interest.

\section{References}

1. Lienhart, W.; Ehrhart, M.; Grick, M. High frequent total station measurements for the monitoring of bridge vibrations. J. Appl. Geodesy 2017, 11, 1-8. [CrossRef]

2. Lienhard, W.; Ehrhart, M. State of the Art of Geodetic Bridge Monitoring. In Proceedings of the International Workshop of Structural Health Monitoring (IWSHM), Stanford, CA, USA, 1-3 September 2015; pp. 449-456.

3. Çelebi, M.; Sanli, A. GPS in Pioneering Dynamic Monitoring of Long-Period Structures. Earthq. Spectra 2002, 18, 47-61. [CrossRef]

4. Chen, Y.; Huang, D.; Ding, X.; Xu, Y.L.; Ko, J.M. Measurement of vibrations of tall buildings with GPS: A case study. In Proceedings of the 6th Annual International Symposium on NDE for Health Monitoring and Diagnostics, Newport Beach, CA, USA, 4 March 2001; SPIE: Washington, DC, USA, 2001; pp. 477-483.

5. Roberts, G.W.; Meng, X.; Dodson, A.H. The use of Kinematic GPS and Triaxial Accelerometers to Monitor the Deflections of Large Bridges. In Proceedings of the 10th FIG International Symposium on Deformation Measurement, Orange, CA, USA, 19-22 March 2001; pp. 19-22.

6. Ogaja, C.; Wang, J.; Rizos, C. Detection of Wind-Induced Response by Wavelet Transformed GPS Solutions. J. Surv. Eng. 2003, 129, 99-104. [CrossRef]

7. Meng, X.; Dodson, A.H.; Roberts, G.W. Detecting bridge dynamics with GPS and triaxial accelerometers. Eng. Struct. 2007, 29, 3178-3184. [CrossRef]

8. Marendič, A.; Kapović, Z.; Paar, R. Possibilities of Surveying Instruments in Determination of Structures Dynamic Displacements. Geod. List 2013, 3, 175-190.

9. Marendić, A. Primjena Geodetskih Mjernih Sustava u Nadgledanju Građevina s Naglaskom na Praćenje Dinamičkih Pomaka. Ph.D. Thesis, University of Zagreb, Zagreb, Croatia, 2011.

10. Kaloop, M.R.; Yigit, C.O.; Hu, J.W. Analysis of the dynamic behavior of structures using the high-rate GNSS-PPP method combined with a wavelet-neural model: Numerical simulation and experimental tests. Adv. Space Res. 2018, 61, 1512-1524. [CrossRef]

11. Koo, K.Y.; Brownjohn, J.M.W. Structural health monitoring of the Tamar suspension bridge. Struct. Control. Health Monit. 2013, 20, 609-625. [CrossRef]

12. Psimoulis, S.; Stiros, S. Measuring deflections of a Short-span Railway Bridges Using Robotic Total Station. J. Bridge Eng. 2013, 18, 182-185. [CrossRef]

13. Marendić, A.; Paar, R.; Grgac, I.; Damjanović, D. Monitoring of Oscillations and Frequency Analysis of the Railway Bridge "Sava" Using Robotic Total Station. In Proceedings of the 3rd Joint International Symposium on Deformation Monitoring (JISDM), Vienna, Austria, 30 March-1 April 2016.

14. Marendić, A.; Paar, R.; Duvnjak, I.; Buterin, A. Determination of Dynamic Displacements of the Roof of Sports Hall Arena Zagreb. In Proceedings of the FIG, 6th International Conference on Engineering Surveying, Prague, Czech Republic, 3-4 April 2014.

15. Psimoulius, P.; Stiros, S. Measurement of Deflections and Oscillation Frequencies of Engineering Structures Using Robotic Theodolites (RTS). Eng. Struct. 2007, 29, 3312-3324. [CrossRef]

16. Kopačik, A.; Kyronović, P.; Kadlecikova, V. Laboratory Tests of Robotic Stations. In Proceedings of the FIG Working Week, Cairo, Egypt, 16-20 April 2005.

17. Radovanović, R.S.; Teskey, W.F. Dynamic Monitoring of Deforming Structures: GPS Versus Robotic Tacheometry Systems. In Proceedings of the 10th symposium of deformation measurements, Orange, CA, USA, 19-22 March 2001.

18. Lekidis, V.; Tsakiri, M.; Makra, K.; Karakostas, C.; Klimis, N.; Sous, I. Evaluation of dynamic response and local soil effects of the Evripos cable-stayed bridge using multi-sensor monitoring systems. Eng. Geol. 2005, 79, 43-59. [CrossRef]

19. Ceryova, I.; Kubanka, P.; Kopačik, A.; Kyrinovič, P. Dynamic test of Robot stations. In Proceedings of the International Congress of Deformations Measurement, FIG, Washington, DC, USA, 19-26 April 2002. 
20. Chua, S.C. Testing of Robotic Total Stations for Dynamic Tracking. Ph.D. Thesis, University of Southern Queensland, Darling Heights, QLD, Australia, 2004.

21. Gikas, V.; Daskalakis, S. Full Scale Validation of Tracking Total Stations Using a Long Stroke Electrodynamic Shaker. In Proceedings of the 13th FIG Congress Shaping the Change, Munich, Germany, 8-13 October 2006.

22. Cosser, E.; Roberts, G.W.; Meng, X.; Dodson, A.H. Measuring the dynamic deformation of bridges using a total station. In Proceedings of the 11th FIG symposium of Deformation Monitoring, Santorini, Greece, 25-28 May 2003.

23. Yi, Z.; Kuang, C.; Wang, Y.; Yu, W.; Cai, C.; Dai, W. Combination of High- and Low-Rate GPS Receivers for Monitoring Wind-Induced Response of Tall Buildings. Sensors 2018, 18, 4100. [CrossRef] [PubMed]

24. Yang, X.; Stewart, K.; Tang, L.; Xie, Z.; Li, Q. A Review of GPS Trajectories Classification Based on Transportation Mode. Sensors 2018, 18, 3741. [CrossRef] [PubMed]

25. Novakovic, G.; Marendić, A.; Grgac, I.; Paar, R.; Ilijaš, R. Locata-A New Technology for High Precision Outdoor and Indoor Positioning. Geod. List 2015, 69, 279-304.

26. Marendić, A.; Paar, R.; Damjanović, D. Measurement of bridge dynamic displacements and natural frequencies by RTS. J. Croat. Assoc. Civ. Eng. 2017, 69, 281-294. [CrossRef]

27. Poyraz, F. Uncertainty in the determination of fault locking depth and strike slip rates by GNSS measurements. Teh. Vjesn. Tech. Gaz. 2016, 23, 107-114. [CrossRef]

28. Grgić, I.; Repanić, M.; Malović, I. Preliminary results of combined geodetic methods in monitoring. Teh. Vjesn. Tech. Gaz. 2017, 24, 301-308. [CrossRef]

29. Guntel, A.; Karabork, H.; Karasaka, L. Accuracy of Control Point Distribution for Different Terrain Types on Photogrammetric Block. Tech. Gaz. 2018, 25, 66-74.

30. Ilçi, V.; Ozulu, I.M.; Arslan, E.; Alkan, R.M. Investigation on the Accuracy of Existing Qibla Directions of the Mosques from Different Periods: A Case Study in Çorum City, Turkey. Tech. Gaz. 2018, 25, 1642-1649. [CrossRef]

31. Motoh, T. Možnost Merjenja Dinamičnega Odziva Konstrukcij z Nekontaktnimi Geodetskimi Metodami. Master's Thesis, University of Maribor, Maribor, Slovenia, 2017.

32. Muršec, L. Sinhronizacija geodetskih in fizikalnih meritev pri izvedbi monitoringa studenške brvi. Master's Thesis, University of Maribor, Maribor, Slovenia, 2019.

33. Press, W.H.; Teukosky, S.A.; Vellerling, W.T.; Flannery, B.P. Numerical Recipies in C-The art of scientific computing. Math. Gaz. 1988, 73, 167-170.

34. Lomb, N.R. Least-squares frequency analysis of unequally spaced data. Astrophys. Space Sci. 1976, 39, 447-462. [CrossRef] 